\title{
Epitopes of Apolipoprotein B-100 and B-48 in Both Liver and Intestine Expression and Evidence for Local Synthesis in Recessive Abetalipoproteinemia
}

Robin P. F. Dullaart, Ben Speelberg, Henk-Jan Schuurman, Ross W. Milne, Louis M. Havekes, Yves L. Marcel, Hans J. Geuze, Mieke M. Hulshof, and D. Willem Erkelens

Department of Internal Medicine, Institute for Pathology, and Department of Cell Biology, University Hospital, 3511 GV Utrecht, The Netherlands; Gaubius Institute, Health Research Division Toegepast Natuurkundig Onderzock, 2313 AD Leiden, The Netherlands; Laboratory of Lipoprotein Metabolism, Clinical Research Institute of Montreal, Montreal, H2W 1R7, Quebec, Canada

\begin{abstract}
The presence of apolipoprotein (apo) $B$ in liver and intestine from a patient with abetalipoproteinemia was evaluated by immunohistochemistry with a polyclonal and six monoclonal antibodies to different apo B-48 and B-100 epitopes. In normal liver, apo $B$ was present inside and outside hepatocytes. The patients liver exhibited staining in the cytoplasm with the polyclonal and three monoclonal antibodies. By immunoelectronmicroscopy, apo B was found to be present in the smooth endoplasmatic reticulum and the Golgi complex. Normal intestinal epithelium was labeled with polyclonal and all monoclonal antibodies, including those specific for apo B-100. The patients epithelium stained with polyclonal and six monoclonals, and apo $B$ was present in the Golgi complex.

Thus, normal intestinal mucosa expressed apo B-48 and B-100 epitopes, which indicates apo B-100 synthesis in the gut. The synthesis of the apo $B$ molecule in the patient seems to be retained in both liver and gut, which suggests a posttranslational defect.
\end{abstract}

\section{Introduction}

Apolipoprotein (apo) $)^{1} \mathrm{~B}$ is an obligatory protein constituent of chylomicrons, very low density lipoproteins (VLDL: $d<1.006$ $\mathrm{g} / \mathrm{ml}$ ), and low density lipoproteins (LDL: $d$ 1.006-1.063 g/ml). It is present in plasma primarily in two forms, which are designated apo B-48 and apo B-100 according to a centile nomenclature system (1). Apo B is the most poorly characterized apolipoprotein, due to its chemical and physical properties. In man, apo B-100 is synthesized in the liver and is found in VLDL and LDL, whereas apo B-48 is synthesized in the intestine and is a constituent of chylomicrons (2). Apo B-48 is produced in the rat both in the liver and the intestine $(3,4)$. Minor quantities of apo B-100 have been isolated from human thoracic duct lymph (1), but not (4), or in only trace amounts, from rat mesenteric duct lymph (5). Apo B-48 and apo B-100 are closely related

Address reprint requests to Dr. Erkelens, Department of Internal Medicine, University Hospital Utrecht, Catharijnesingel 101, 3511 GV Utrecht, The Netherlands. 1986.

Received for publication 23 January 1986 and in revised form 5 June

1. Abbreviations used in this paper: apo, apolipoprotein; apo B, apo B-48, and apo B-100, apolipoproteins B, B-48, and B-100, respectively.

J. Clin. Invest.

(c) The American Society for Clinical Investigation, Inc. $0021-9738 / 86 / 11 / 1397 / 08 \$ 1.00$

Volume 78, November 1986, 1397-1404 structurally $(6,7)$, but their synthesis is possibly under different genetic control (6). Previous studies using monoclonal antibodies against human LDL showed a possible sequence homology between the two protein moieties (7).

Classical abetalipoproteinemia is a very rare autosomal recessive disorder, which was first described in 1950 by Bassen and Kornzweig (8). Its hallmark is the absence of apo B- and apo B-containing lipoproteins from plasma $(9,10)$. Heterozygotes are phenotypically normal. Other apo B deficiency syndromes include familial hypobetalipoproteinemia, which is transmitted as an autosomal dominant trait, where heterozygotes have LDL cholesterol levels $\sim 50 \%$ of normal and homozygotes are clinically and biochemically similar to patients with recessive abetalipoproteinemia $(10,11)$; normotriglyceridemic abetalipoproteinemia, in which apo B-100 is absent from plasma (1214); and familial hypobetalipoproteinemia with chylomicronemia, which is characterized by very low levels of LDL and fasting chylomicronemia (15). The molecular basis of the various apo $B$ deficiency syndromes has not yet been identified. In recessive abetalipoproteinemia defects in apo B synthesis, intracellular assembly, secretion of apo B-containing lipoproteins, and rapid catabolism of apo B have been hypothesized $(12,16)$. Clinical symptoms of this disorder include malabsorption of fat as a direct result of defective chylomicron transport; neuromuscular manifestations, such as spinocerebellar degeneration and peripheral neuropathy; retinitis pigmentosa; and acanthocytosis of erythrocytes (16). Intestinal biopsies invariably show accumulation of fat in the enterocytes (10). Using rabbit antiserum to human LDL in immunohistochemistry, apo B could not be demonstrated in intestinal epithelial cells from two cases with abetalipoproteinemia (17). Hepatic steatosis is often present, but usually without clinical manifestation of liver disease.

In this report a patient with recessive abetalipoproteinemia is described. We had the opportunity to use a series of monoclonal antibodies to various epitopes on apo B (7) in an immunohistochemical study on the expression of apo B in normal liver and intestine and to document the deficiency in this patient at the tissue level. Since immunohistochemical presence does not prove local synthesis, immunoelectronmicroscopy was performed with special attention to the endoplasmatic reticulum, the Golgi complex, and secretion granules.

\section{Methods}

\section{Case report}

A 29-yr-old female was referred for further evaluation of abetalipoproteinemia, which was diagnosed elsewhere at the age of 25 . She was the only child of Dutch consanguinous parents. Her parents and her two half-brothers were healthy. Her youth was uneventful, although she showed a notable intolerance for fatty foods. Because of her clumsiness, 
the patient was seen by a neurologist when she was 14. Slight pes cavus, absence of tendon reflexes, and an intention tremor were observed, and a tentative diagnosis of a heredo familial spinocerebellar degenerative condition was made. Loss of visual acuity and retinitis pigmentosa were observed when she was 25 yr of age. No beta or prebetalipoproteins were seen on agarose gel electrophoresis of plasma. A blood smear showed that $60-70 \%$ of the erythrocytes were acanthocytes. The diagnosis of abetalipoproteinemia was made. She was treated with megadoses of orally administered vitamin $\mathrm{E}$ ( $5 \mathrm{~g}$ daily) in an attempt to delay the progression of the neurological and retinal lesions $(18,19)$. During the 1st year on vitamin $\mathrm{E}$ treatment, her neurological condition stabilized, but afterwards she noted progression and further decrease of vision.

At referral she appeared well nourished, weighing $46 \mathrm{~kg}$ and standing 1.53-m tall. Her skin was scaly, probably as a result of essential fatty acid deficiency (20). Visual power was considerably decreased (vision, left eye, $0.5 / 60$; right eye, $1 / 60$ ). Visual-evoked potential recording, using a pattern reversal checkerboard, was unsuccessful because of impaired vision. When flashing lights were used, a normal latency period (left eye, $116 \mathrm{~ms}$; right eye, $109 \mathrm{~ms}$ ) and amplitude (left eye, $5 \mu \mathrm{V}$; right eye, $9 \mu \mathrm{V}$ ) were recorded. Her gait was atactic. Electromyographic studies showed polyneuropathy with axonal degeneration.

On multiple occasions, plasma triglyceride was either undetectable or very low $(0.1 \mathrm{mmol} / \mathrm{liter})$. Cholesterol was markedly decreased (1.3 mmol/liter). To obtain detailed information on the cholesterol distribution in various lipoprotein fractions, plasma was separated by modified density gradient ultracentrifugation (21). $4 \mathrm{ml}$ plasma was adjusted to $d$ $=1.25 \mathrm{~g} / \mathrm{ml}$ with solid $\mathrm{KBr}$, pipetted into $14 \times 95-\mathrm{mm}$ polyallomer tubes, and then overlayered with $2.8 \mathrm{ml}$ of a $\mathrm{KBr} / \mathrm{NaCl}, 1 \mathrm{mM}$ EDTA solution of $d=1.063 \mathrm{~g} / \mathrm{ml} ; 2.8 \mathrm{ml}$ of $d=1.019 \mathrm{~g} / \mathrm{ml}$; and $1.5 \mathrm{ml}$ of $d$ $=1.006 \mathrm{~g} / \mathrm{ml}$. Samples were centrifuged for $22 \mathrm{~h}$ at $4^{\circ} \mathrm{C}$ at $113,600 \mathrm{~g}$ in a SW 40 Ti rotor in a Beckman L8-80 ultracentrifuge. Fractions of 0.5 $\mathrm{ml}$ were carefully aspirated, cholesterol was assayed by an enzymatic method (cat. No. 237 574; Diagnostica Kit, Boehringer Mannheim, Federal Republic of Germany). A control plasma sample was processed identically. In contrast to normal plasma, the plasma of the patient contained one cholesterol peak only, which occurred in the density range of high density lipoprotein ${ }_{2}\left(\mathrm{HDL}_{2}\right)(d$ 1.063-1.125 $\mathrm{g} / \mathrm{ml})$, with extensions in the $\mathrm{LDL}$ and $\mathrm{HDL}_{3}$ range (Fig. 1).

Plasma apo B was assayed by kinetic immunoturbidimetry as previously described for albumin (22) in a Multistat I Centrifugal Analyzer (Instrumentation Laboratories, IJsselstein, The Netherlands), using polyclonal sheep anti-human LDL antiserum (cat. No. 726 494; Boehringer Mannheim) and a polyclonal rabbit anti-human apo B antiserum, prepared as described below. With this apo B assay, which has a detection limit of $1 \mathrm{mg} / \mathrm{dl}$, apo B could not be demonstrated in fasting plasma of the patient.

Analysis of plasma fatty acid concentrations showed an increase of 20:3 fatty acid (references 5, 8, and 11; icosatrienoic acid) as an indication of essential fatty acid deficiency $(0.9 \%$, expressed as percentage of total plasma fatty acids after saponification and reesterifying with methanol, normal $<0.2 \%$ ). Out of the fat soluble vitamins, vitamin $A$ and vitamin E concentrations were decreased (0.5 $\mu \mathrm{mol} /$ liter, normal range 0.9-3.5 $\mu \mathrm{mol} /$ liter, and $6.9 \mu \mathrm{mol} / \mathrm{liter}$, normal range 18.0-47.0 $\mu \mathrm{mol} / \mathrm{liter}$, respectively). Prothrombin time and vitamin $\mathrm{D}_{3}$ metabolites were normal. Normal values were obtained for hematocrit, white cell count, and platelet count. Plasma calcium, urea nitrogen, creatinine, parameters of liver function, and phytanic acid were normal. Thyroid function and adrenal function, assessed by ACTH stimulation, were not impaired. Fecal fat excretion was $4.7 \mathrm{~g} / \mathrm{d}$ on a diet containing $20 \mathrm{~g} / \mathrm{d}$ of fat (coefficient of absorption: $76 \%$ (normal $>95 \%$ ). An oral fat load was performed with $2 \mathrm{~g}$ of fat per kilogram weight, but no increase in plasma triglyceride was observed between 0 and $8 \mathrm{~h}$ after the test meal.

The mother of the patient consented to clinical investigation. No abnormalities were found on physical examination. Plasma lipids (cholesterol, $8.2 \mathrm{mmol} / \mathrm{liter}$, and triglyceride, $2.6 \mathrm{mmol} / \mathrm{liter}$ ) and apo $\mathrm{B}$ concentration $(120 \mathrm{mg} / \mathrm{dl})$ were not decreased. The mode of inheritance of the patient's disorder was apparently autosomal recessive, and she was considered to have recessive abetalipoproteinemia. In an attempt to treat

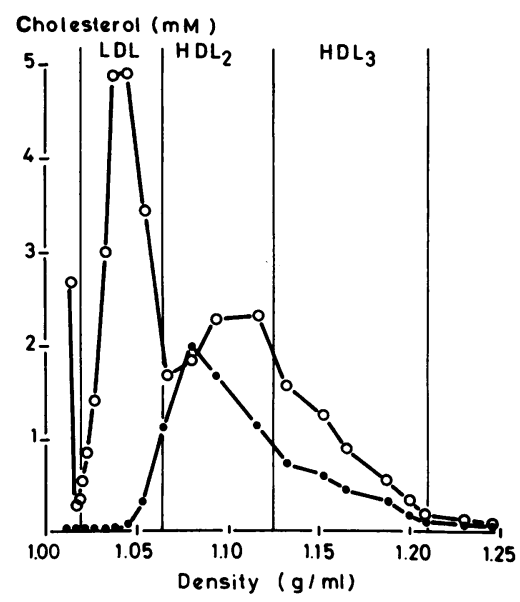

Figure 1. Plasma lipoprotein fractions, obtained by density gradient ultracentrifugation. (๑) Cholesterol concentration in plasma fractions of the abetalipoproteinemic patient. (0) Cholesterol concentration in plasma fractions of a control subject.

the essential fatty acid deficiency and to increase plasma vitamin $A$ and vitamin $\mathrm{E}$ concentrations, $500 \mathrm{ml}$ of $10 \%$ artificial triglyceride emulsion (Intralipid; KabiVitrum, Amsterdam, The Netherlands), enriched with $1.5 \mathrm{mg}$ vitamin A (Vitalipid; KabiVitrum) and $200 \mathrm{mg}$ vitamin E (Ephynal; Hoffmann-La Roche, Basel, Switzerland), was administered intravenously at weekly intervals. After 5 wk of therapy, vitamin $E$ increased to $8.9 \mu \mathrm{mol} / \mathrm{liter}$ and vitamin $A$ increased to $0.9 \mu \mathrm{mol} / \mathrm{liter}$.

\section{Tissue specimens}

Liver and jejunal biopsies from the patient were obtained with informed consent, and the latter biopsy was done after an overnight fast. After 6 mo, liver and jejunal biopsies were repeated, 1 wk after the last administration of the artificial triglyceride emulsion, to evaluate possible adverse effects of this treatment on intracellular fat accumulation. Controls included five human liver biopsies and two jejunum biopsies. A piece of brain tissue was obtained at autopsy from a patient who died of a nonimmunological disorder. These control tissues showed a normal architecture in histopathology.

\section{Anti-apo B antibodies}

Polyclonal rabbit anti-human apo $B$ antiserum was prepared by immunizing a rabbit with human LDL, and the antiserum was isolated in a narrow density range $(d 1.035-1.045 \mathrm{~g} / \mathrm{ml})$. The antiserum did not show cross-reactivity with apo A-I, apo A-II, apo C-II, apo C-III, or apo $\mathrm{E}$ as evaluated by double immunodiffusion (Ouchterlony Technique) using serial dilutions of both antiserum and antigen.

Six monoclonal antibodies against human LDL, which were obtained from hybridomas, were the product of a cell fusion between cells of the plasmacytoma cell line SP 2-0 (23) and isolated spleen cells from BALB/c mice that were previously immunized with human LDL. Details of the procedure and characterization of the antibodies have been described elsewhere $(7,24)$. Based on co-titration experiments with these monoclonal antibodies, a hypothetical map of epitopes on apo B-100 and apo B-48 has been proposed (7), which is summarized in Fig. 2.

Monoclonal 101
antibodies

Figure 2. Hypothetical map of epitopes on apo B-100 and apo B-48 using a panel of monoclonal antibodies. The coding of the various monoclonal antibodies is identical to that in reference 7. 


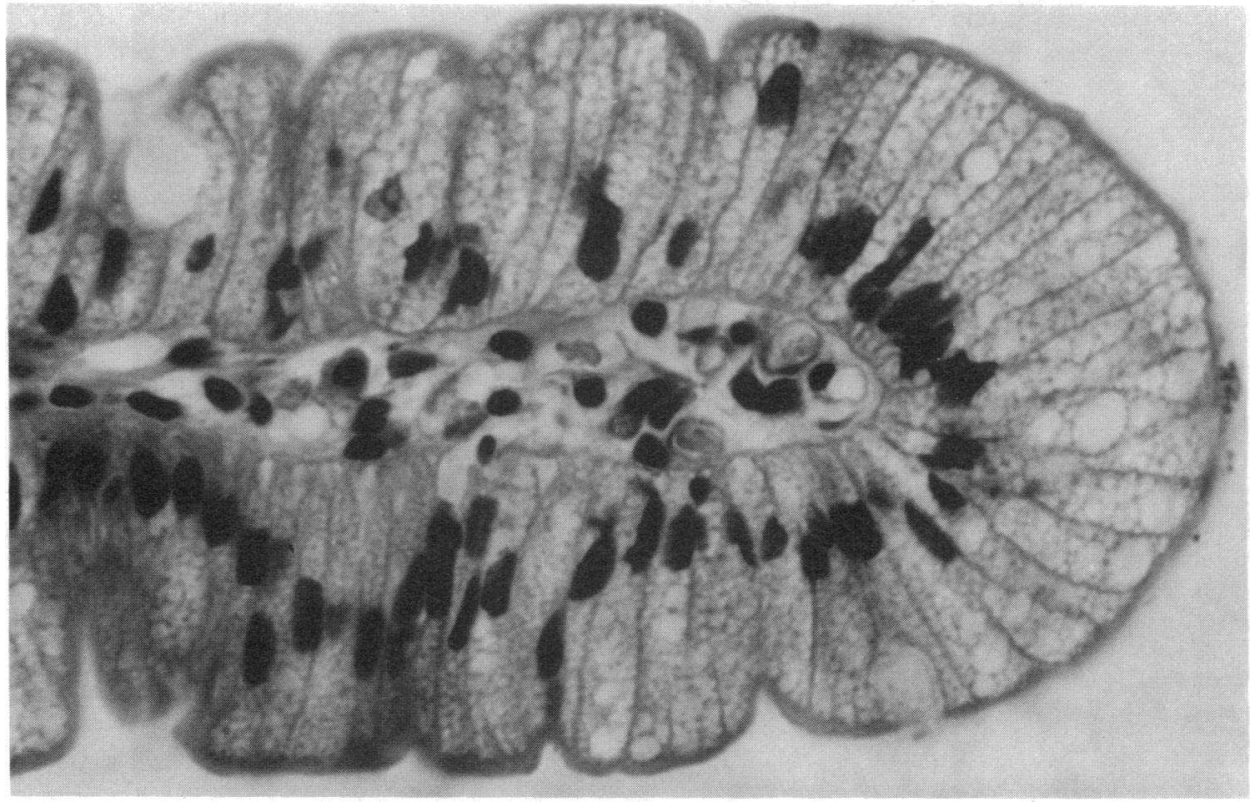

Figure 3. Jejunal biopsy section from the patient with abetalipoproteinemia, obtained after an overnight fast. The specimen was stained by hematoxylin and eosin. Note the numerous small, fat-containing vacuoles in the enterocytes at the top of the villus. Hematoxylin and eosin staining. $\times 640$.

\section{Immunohistochemistry}

Part of the biopsies were fixed in $4 \%$ formalin and embedded in paraffin. For routine histopathology, sections were stained with hematoxylin and eosin. Another part of the biopsy was snap-frozen and stored below $-70^{\circ} \mathrm{C}$. Six $\mu \mathrm{m}$ sections were processed in indirect immunofluorescence, using the polyclonal rabbit anti-human apo B antiserum in the first incubation, and fluorescein isothiocyanate-labeled horse anti-rabbit antibody (Central Laboratory of the Red Cross Blood Transfusion Service, Amsterdam, The Netherlands) in the second incubation. After each incubation the sections were extensively rinsed in phosphate-buffered saline (PBS; pH 7.4). Sections were mounted in PBS, supplemented with $10 \%$ vol/vol glycerol, and viewed using a Leitz Laborlux 12 fluorescence mi- croscope equipped with $\mathrm{HBO} 100$ epi-illumination and a $\mathrm{K} 2$ filter combination, at $25 \times$ or $50 \times$ water immersion objectives, $12 \times$ oculars. The monoclonal antibodies were applied in an indirect immunoperoxidase procedure. The first incubation included the monoclonal antibody; the second one, rabbit anti-mouse immunoglobulin, conjugated to horseradish peroxidase (Dakopatts, Copenhagen, Denmark). Staining was performed using 3-amino-9-ethylcarbazol.

No staining was observed, either when the monoclonal antibodies were omitted in the immunoperoxidase procedure, or when nonimmune rabbit serum instead of the polyclonal rabbit anti-human apo B antiserum was applied in immunofluorescence. None of the monoclonal antibodies, nor the polyclonal antiserum, gave labeling of the brain tissue sections.

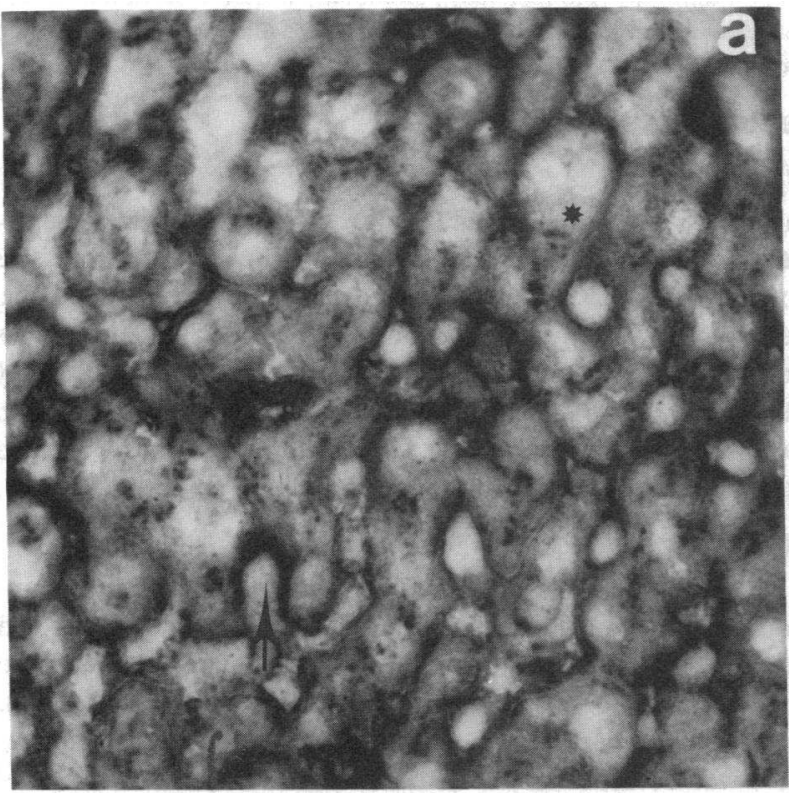

Figure 4. Labeling of liver sections with monoclonal apo B antibody 3A8 (indirect immunoperoxidase, $\times 470$ ). (a) Normal liver. The labeling of the cytoplasm of hepatocytes is visible in a fine and more coarse granular pattern with nonstaining of the nucleus (*); the sinusoidal

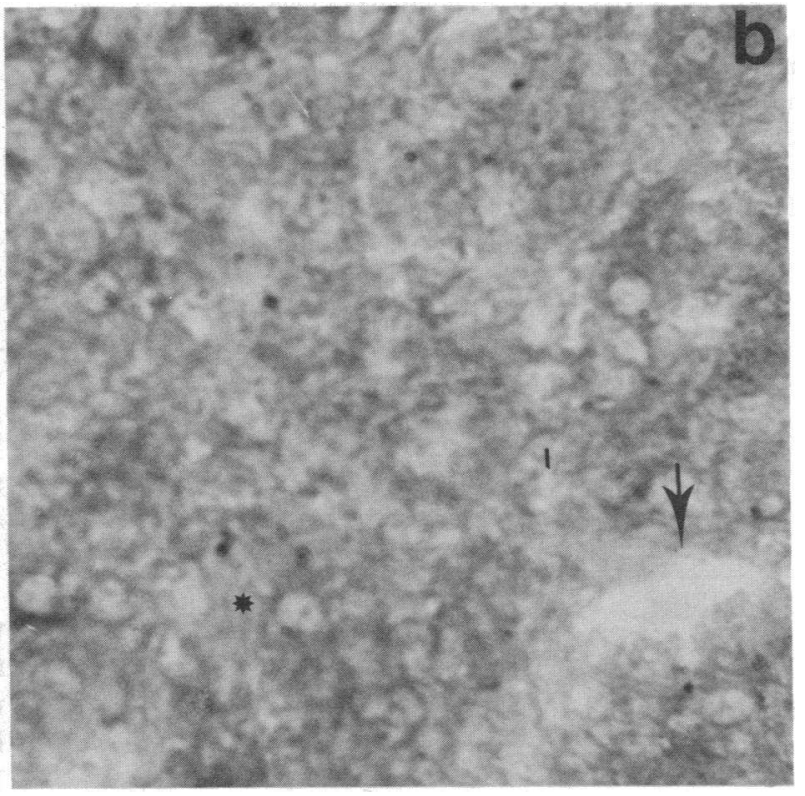

spaces are stained more intensely (arrow) than the sinusoids. (b) Liver of a patient with abetalipoproteinemia. The sinusoids are empty (arrow) and the cytoplasm of hepatocytes is stained faintly with exclusion of nuclei and fat vacuoles (*). 


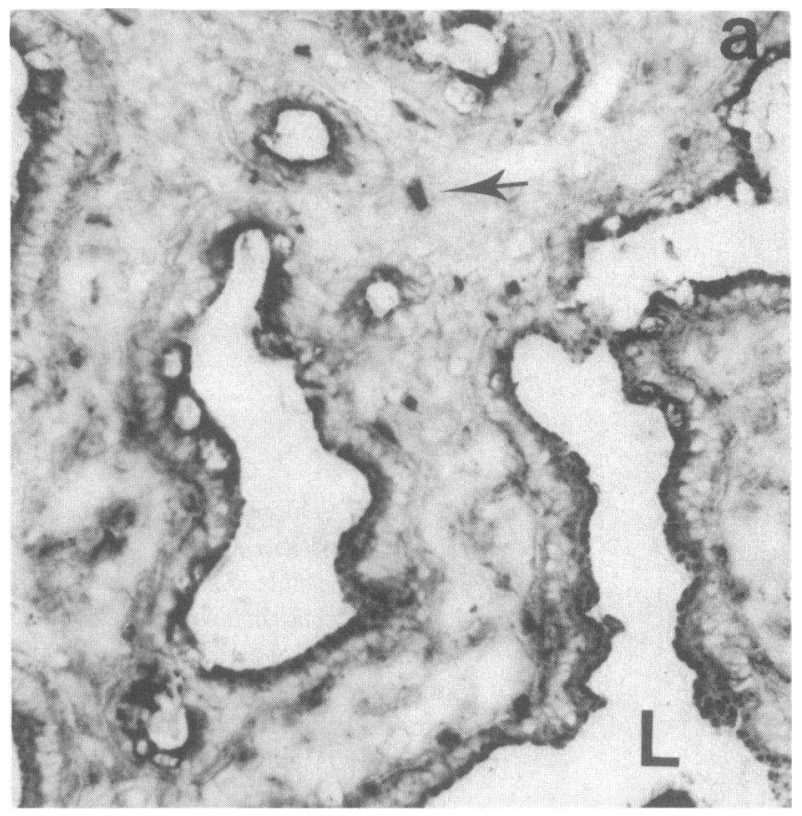

Figure 5. Labeling of jejunal biopsy sections with monoclonal apo B antibody $3 \mathrm{A8}$ (indirect immunoperoxidase, $\times 470)$. $(a)$ Normal intestine. Labeling of the cytoplasm of intestinal mucosal cells is apparent, with the most intensive staining at the side of the lumen $(L)$. The

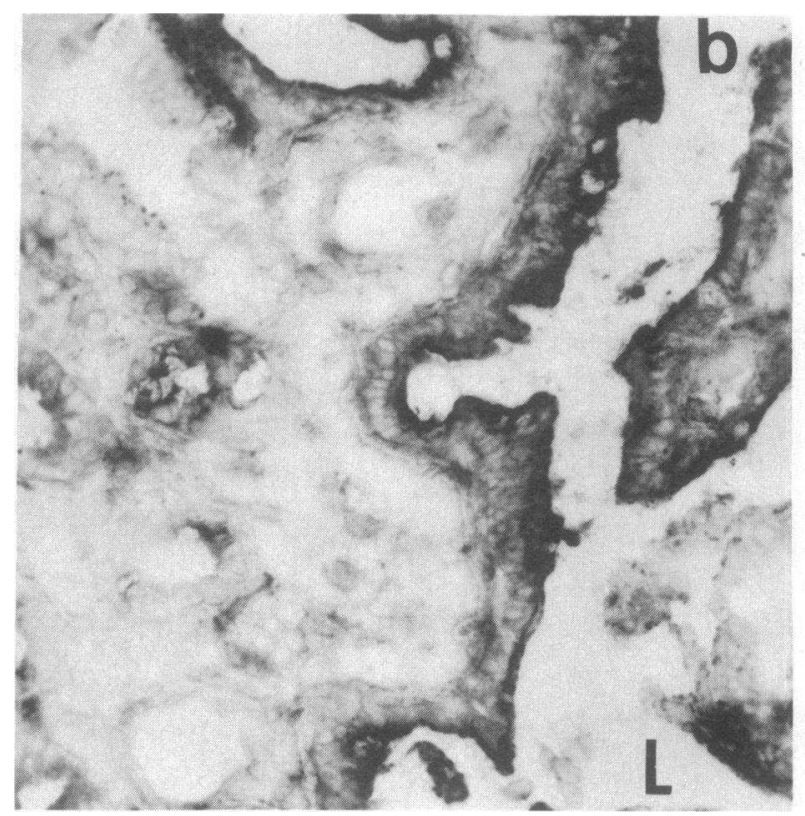

blood vessels in the stroma are positive as indicated by the arrow. (b) Abetalipoproteinemic intestine. There is specific staining of apo B in the mucosal epithelium only, most intensively at the luminal $(L)$ side. The stroma of blood vessels do not show.

binding sites were labeled with $6 \mathrm{~nm}$ protein A-colloidal gold (26-28). A second swine anti-mouse (Nordic Immunological Laboratories, Tilburg, The Netherlands) or goat anti-mouse (Janssen Farmaceutica, Beerssen, Belgium) IgG was used before the protein A-gold labeling in case of the monoclonals. The sections were stained with uranylacetate and embedded in methylcellulose $(27,29)$. Controls included ultrathin sections of liver or intestine that were incubated with either protein Acolloidal gold alone, i.e., without anti-apo B antibody, or the same with a second antibody, or the same and immunoserum against irrelevant antigens ([i] antiamylase antibody [polyclonal], or [ii] anti-T lymphocyte receptor antibody [monoclonal]), and finally ultrathin section of uterus tissue, incubated with protein A-colloidal gold and polyclonal anti-apo B antibody.

\section{Results}

\section{Histopathology}

The liver biopsy of the patient showed fatty vacuoles in the hepatocytes, especially in zone 2 of the acinus. Apart from this moderate steatosis, no other abnormalities were present. The jejunal biopsy showed a normal architecture. The enterocytes contained numerous small vacuoles at the luminal side, notably at the top of the villi (Fig. 3), which contained fat on fat staining. No difference in intracellular fat accumulation was observed between the first and second liver and jejunal biopsies.

\section{Immunohistochemistry}

LIVER. In sections of normal liver, the polyclonal rabbit antibody and the various monoclonal antibodies to apo B labeled the cytoplasm of the hepatocytes in a fine granular pattern. There was also a bright continuous staining along the sinusoidal spaces. Blood vessels, when present, showed staining of the endothelium. There was no difference in pattern or intensity of staining between the monoclonal reagents.

Liver sections of the patient revealed, using the polyclonal antiserum, a faint staining of the cytoplasm of the hepatocytes. The staining was considered specific, since it was not present 
when the antibody was used after absorption with normal LDL; in addition, liver sections were not labeled when incubated with nonimmune rabbit serum. Blood vessels and sinusoidal spaces were negative.

The various monoclonal reagents labeled in different patterns. No reaction was seen using monoclonal antibodies 2D8, $3 F 5$, and 5E11. A faint to very faint staining of the cytoplasm of the hepatocytes in a fine granular pattern was observed using antibodies 1D1, 4G3, and 3A8. Apart from the labeling of antibody 1D1, which was observed only in the second biopsy, no difference in labeling between the two biopsies was noticed. Blood vessels and sinusoidal spaces were negative using all monoclonal

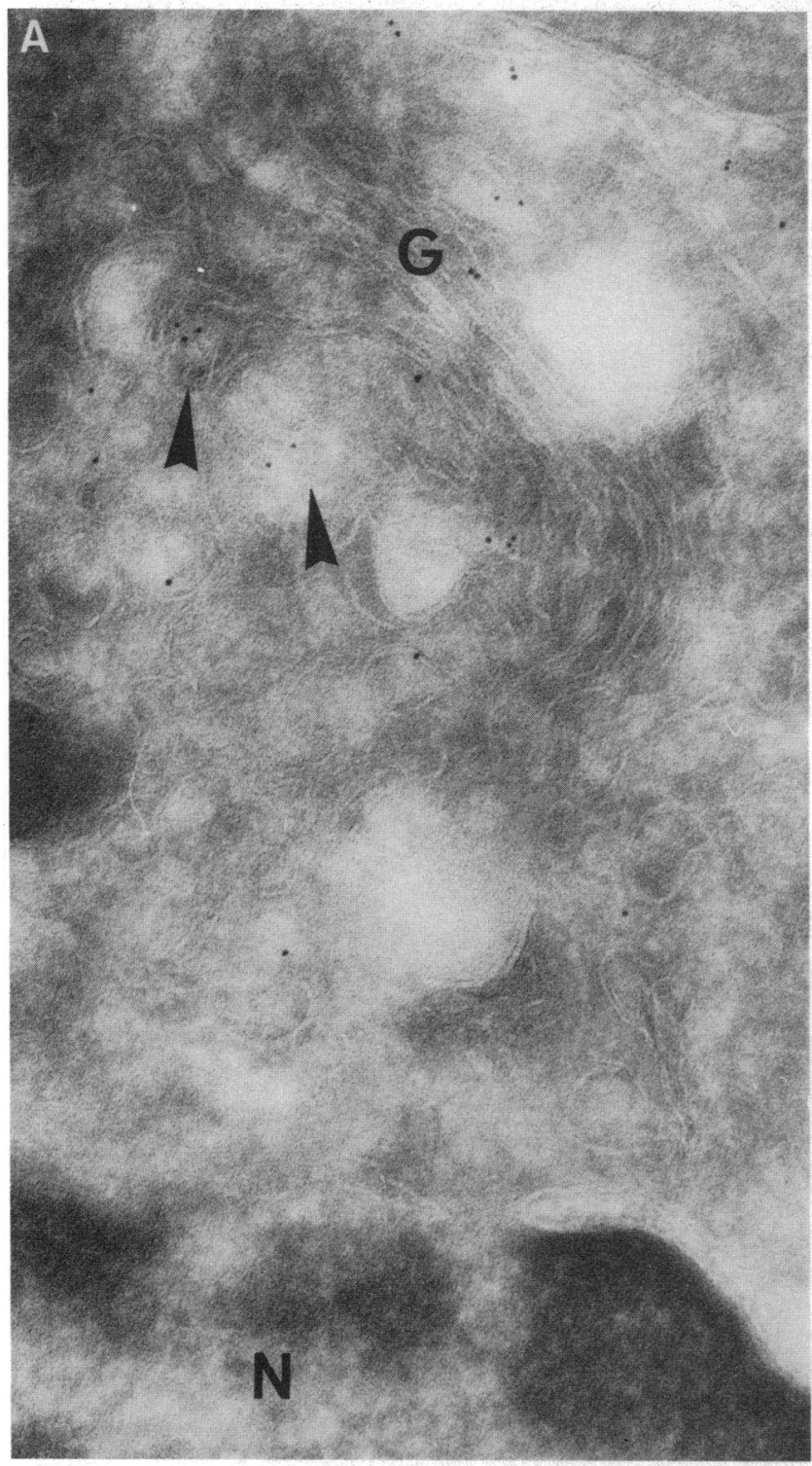

Figure 6. Electron micrographs of ultrathin cryosections of liver tissue of the abetalipoproteinemic patient. The sections were incubated with polyclonal anti apo B and labeled with $6 \mathrm{~nm}$ gold particles. $\times 134,000$. (a) Gold particles can be seen over the cisternae of the Golgi complex reagents. Fig. 4 illustrates the labeling of a liver section from a normal control and from the abetalipoproteinemic patient using monoclonal antibody $3 \mathrm{A8}$.

INTESTINE. In sections of control jejunum, either the polyclonal anti-apo $B$ antiserum or one of the monoclonal antibodies gave a granular staining of the enterocytes, especially at the luminal side. The intensity of staining was similar at the top of the villi and in the crypts. Identical labeling occurred, using the various monoclonal reagents.

The staining of the patient's jejunal biopsy using the polyclonal antiserum did not differ quantitatively from the normal picture, except for a more pronounced labeling of the crypt ep-

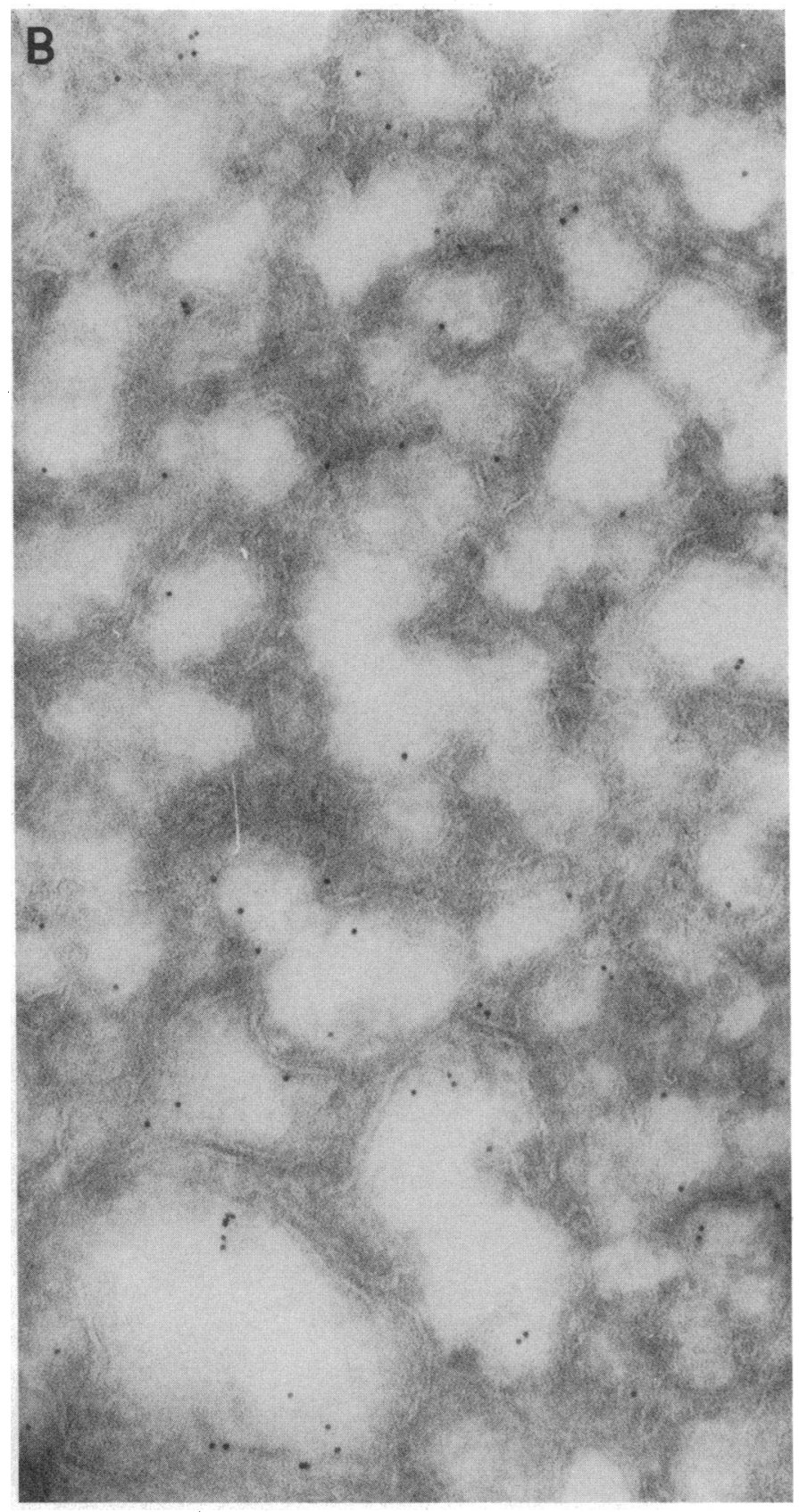

$(G)$ and over developing secretory granules (arrowheads).

$N$, nucleus. (b) Apo B labeling is present in the cisternae of the smooth endoplasmic reticulum. 
ithelium. In addition, the enterocytes were stained by all monoclonal reagents. The intensity of staining was as normal using monoclonal antibodies $1 \mathrm{D} 1,2 \mathrm{D} 8,3 \mathrm{~A} 8$, and 5E11, but was rather faint using 3F5 and 4G3. None of the reagents labeled blood vessels. Both jejunal biopsies of the patient showed similar staining. The staining of a jejunal section from a normal control and from the abetalipoproteinemic patient using monoclonal antibody 3 A8 is illustrated in Fig. 5 .

The results of the labeling of liver and jejunal sections from the patient with abetalipoproteinemia with the panel of six monoclonal antibodies are summarized in Table I.

\section{Immunoelectronmicroscopy}

None of the controls mentioned in the Methods section contained gold labeling. The labeling after incubation of the tissue specimens with the monoclonal antibodies were weak in comparison to the polyclonal. Immunoelectronmicroscopic localization of apo B in the liver of the patient demonstrated gold particles in the cisternae of the Golgi complex and developing secreting granules (Fig. $6 a$ ), and also in the smooth endoplasmatic reticulum (Fig. 6 b). In the patient's intestine electronmicroscopy, gold particles in the Golgi complex (Fig. 7), but also in some of the intercellular spaces, were revealed.

\section{Discussion}

In a patient with recessive abetalipoproteinemia we were able to document expression of apo B epitopes in liver and jejunum, while apo B was not detectable in her plasma. The pattern of staining by polyclonal rabbit anti-human apo B antiserum of

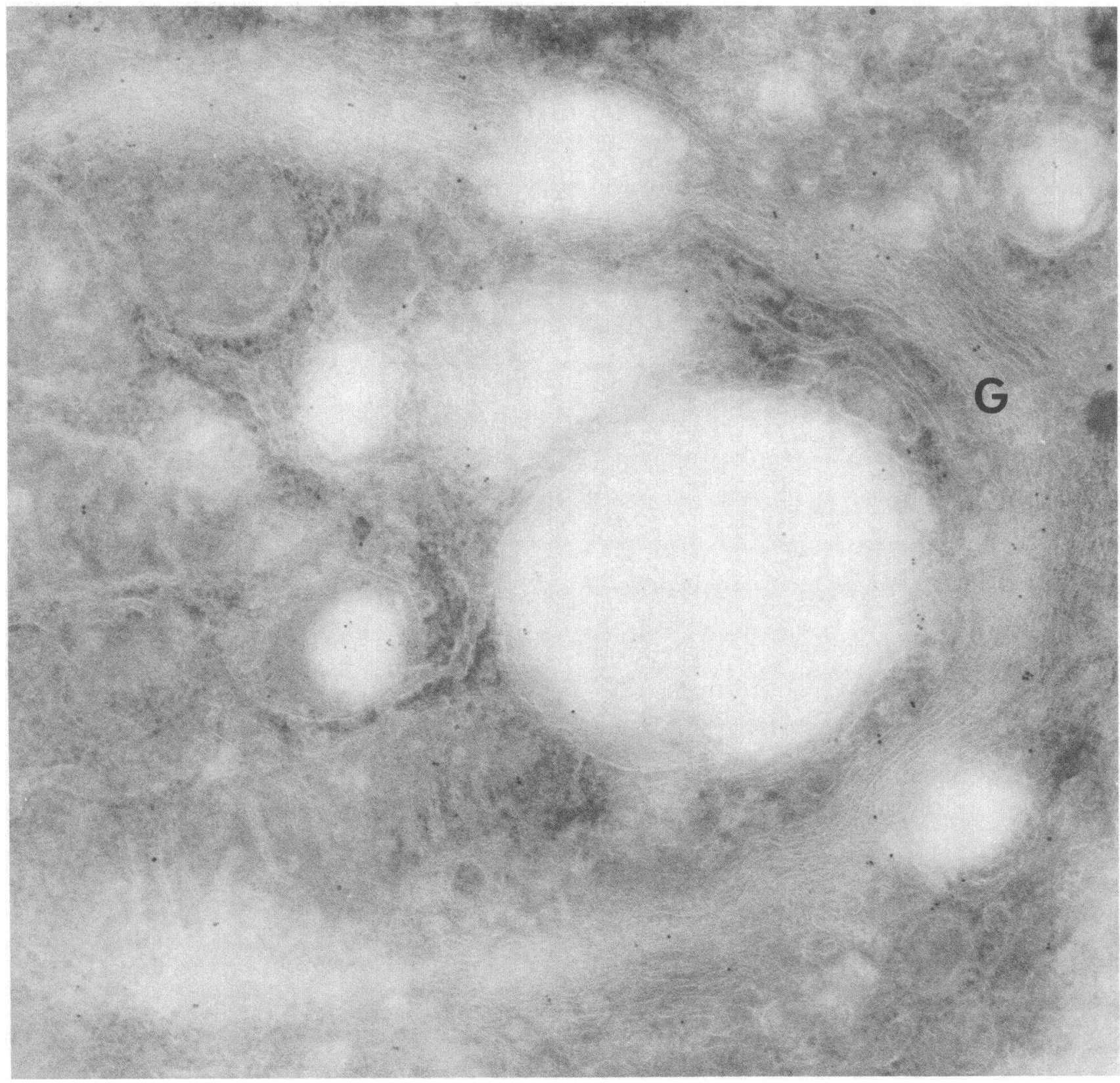

Figure 7. Electron micrograph of the Golgi complex $(G)$ of duodenal cells of the abetalipoproteinemic patient. The section was incubated with polyclonal anti-apo B and labeled with 6-nm gold particles. Gold particles are present in the cisternae of the Golgi complex and in electron-lucent vacuoles at the trans-side of the Golgi stack. $\times 91,000$. 
normal liver and intestine is compatible with the literature (17, 30). In man, apo B was present in enterocytes, especially at the luminal side of the cell (17), using a monospecific anti-human LDL antiserum and in homogenates of duodeno-jejunal absorptive cells (30). In the rat, apo B was demonstrated in the enterocytes $(31,32)$ and in liver tissue, in both cases with a fine granular pattern in the cytoplasm of hepatocytes and along sinusoidal spaces, using polyclonal rabbit anti-rat LDL antisera (32) similar to that used in our present experiment and in our earlier reported (33) results in man.

Using monoclonal antibodies to human apo B, a map of epitopes on apo B-100 and apo B-48 was proposed previously (7). It is commonly assumed that, in human plasma, apo B-100 is of hepatic origin, and that apo B-48 is of intestinal origin (2). Since the two available monoclonal antibodies to epitopes on apo B-48 also react with apo B-100, the similar staining patterns using the different antibodies do not allow any conclusions with respect to human hepatic apo B-48 synthesis.

Although apo B-48 and apo B-100 were present in human thoracic duct lymph (1), the issue of intestinal apo B-100 synthesis has not yet been settled, since the presence of apo B-100 in thoracic duct lymph can be the consequence of drainage of hepatic lymph into this system. The present results, showing labeling of intestinal epithelium with monoclonal antibodies to epitopes on apo B-100, and not reacting with epitopes on apo B-48, suggest that normal jejunum can synthesize both apo B-48 and apo B-100.

However, apo B-48 is undoubtedly the most abundant product of intestinal apo B secretion (1). The genetic basis of apo B heterogeneity remains unknown. The present results are also compatible with the proposed concept (7) that apo B-48 and apo B-100 are products of the same gene and that apo B-48 is a cleavage product of apo B-100. The protein subspecies ultimately secreted in the circulation or lymph could be the result of different posttranslational processing in intestine and hepatocytes.

The clinical disorder of our patient is clearly compatible with recessive abetalipoproteinemia $(10,16)$. Using a polyclonal rabbit anti-human apo B antiserum, apo B was undetectable in plasma, in endothelium of blood vessels, and along sinusoidal spaces. In contrast, the hepatocytes showed a faint but specific staining and the enterocytes labeled normally using this polyclonal antiserum. Furthermore, the patient's intestinal epithelium labeled with all and the hepatocytes labeled with three monoclonal antibodies. The different labeling patterns in liver and jejunum using monoclonal antibodies 2D8, 3F5, and 5E11 are not readily explained, but could be the result of defective modification (such as glycosylation) or defective synthesis of the apo B-100 protein chain in the patient's liver. It could also be the result of a lack in sensitivity of the applied immunohistochemical technique in liver sections. The immunohistochemical data as described in this paper do not provide evidence of whether or not apo B is present in the synthetic apparatus of the patient's liver and gut cells, or whether it is localized in other cellular compartments. However, the highly sensitive immunoelectronmicroscopic technique used (34) shows specific staining of apo $B$ and localization of the gold particles in the smooth endoplasmatic reticulum, the Golgi complex, and secretory granules. In normal jejunal absorptive cells (35) and rat liver cells (36), ultrastructural immunolocalization has been performed before. In view of the localization described by us, the conclusion that apo B, or at least part of the apo B molecule recognized by the antibodies, is synthesized in both the liver and gut of the abetalipoproteinemic patient seems inescapable.

The present results are in contrast with the report of Glickman (17) in which the absence of apo B immunoreactivity in enterocytes of two abetalipoproteinemic patients was documented. Based on these results a genetic defect in the synthesis of the apo B protein has been proposed $(16,17)$. Other theories include disturbances in posttranslational modifications of the apo B protein structure, such as defects in polymerization of the subunits or glycosylation and defects in regulator genes (12). Besides, a defect in secretion of apo B from the cell has been proposed (16). Our results suggest a defect in secretion of apo B or appropriate association with lipids both in liver and intestine. Therefore, it cannot be excluded that recessive abetalipoproteinemia is a heterogeneous disorder and that this patient has a disorder phenotypically identical with recessive abetalipoproteinemia, but with a genetic defect different from other patients described. Very recently, the gene of human apo B-100 has been cloned. By molecular genetic techniques, messenger RNA of apo B-100 has been found in hepatocytes of another abetalipoproteinemic patient (37), which is concordant with the present immunohistochemical study.

\section{Acknowledgments}

Mr. J. G. N. Geertzema and Mr. J. A. J. Mocking are acknowledged for their expert technical assistance. Mrs. S. A. N. van Santen-van Reenen prepared the manuscript. Dr. P. J. M. van Wensen, St. Elisabeth's Gasthuis, Arnhem, The Netherlands, referred the patient to the University Hospital of Utrecht, The Netherlands.

\section{References}

1. Kane, J. P., D. A. Hardman, and H. E. Paulus. 1980. Heterogeneity of apolipoprotein B: isolation of a new species from human chylomicrons. Proc. Natl. Acad. Sci. USA. 77:2465-2469.

2. Mahley, R. W., T. L. Innerarity, S. C. Rall, Jr., and K. H. Weisgraber. 1984. Plasma lipoproteins: apolipoprotein structure and function. J. Lipid Res. 25:1277-1294.

3. Windmueller, H. G., and A. E. Spaeth. 1985. Regulated biosynthesis and divergent metabolism of three forms of hepatic apolipoprotein B in the rat. J. Lipid Res. 26:70-81.

4. Krishnaiak, K. V., L. F. Walker, J. Borensztajn, G. Schonfeld, and G. S. Getz. 1980. Apoprotein B variant derived from rat intestine. Proc. Natl. Acad. Sci. USA. 77:3806-3810.

5. Wu, A. L., and H. G. Windmueller. 1981. Variant forms of plasma apolipoprotein B, hepatic and intestinal biosynthesis and heterogenous metabolism in the rat. J. Biol. Chem. 256:3615-3618.

6. Kane, J. P. 1983. Apoprotein B structural and metabolic heterogeneity. Annu. Rev. Physiol. 45:637-650.

7. Marcel, Y. L., M. Hogue, R. Theolis, Jr., and R. W. Milne. 1982. Mapping of antigenic determinants of human apolipoprotein B using monoclonal antibodies against low density lipoproteins. J. Biol. Chem. 257:13165-13168.

8. Bassen, F. A., and A. L. Kornzweig. 1950. Malformation of the erythrocytes in a case of atypical retinitis pigmentosa. Blood. 5:381-387.

9. Kayden, H. J. 1972. Abetalipoproteinemia. Annu. Rev. Med. 23: 285-296.

10. Malloy, M. J., and J. P. Kane. 1982. Hypolipidemia. Med. Clin. N. Am. 66:469-484.

11. Cottrill, C., C. J. Glueck, V. Leuba, F. Millett, D. Puppione, and W. V. Brown. 1974. Familial homozygous hypobetalipoproteinemia. Metab. Clin. Exp. 23:779-791.

12. Malloy, M. J., J. P. Kane, D. A. Hardman, R. L. Hamilton, and K. B. Dalal. 1981. Normotriglyceridemic abetalipoproteinemia, absence of the B-100 apolipoprotein. J. Clin. Invest. 67:1441-1450. 
13. Herbert, P. N., J. S. Hyams, D. N. Bernier, M. M. Berman, A. L. Saritelli, K. M. Lynch, A. V. Nichols, and T. M. Forte. 1985. Apolipoprotein B-100 deficiency. Intestinal steatosis despite apolipoprotein B-48 synthesis. J. Clin. Invest. 76:403-412.

14. Takashima, Y., T. Kodama, H. lida, M. Kawamura, H. Aburatani, H. Itahura, Y. Akanuma, F. Torkaku, and M. Kawade. 1985. Normotriglyceridemic abetalipoproteinemia in infancy: an isolated apolipoprotein B100 deficiency. Pediatrics. 75:541-546.

15. Steinberg, D., S. M. Grundy, H. Y. I. Mok, J. D. Turner, D. B. Weinstein, W. V. Brown, and J. J. Albers. 1979. Metabolic studies in an unusual case of asymptomatic familial hypobetalipoproteinemia with hypoalphalipoproteinemia and fasting chylomicronemia. J. Clin. Invest. 64:292-301.

16. Herbert, P. N., G. Assmann, A. M. Gotto, Jr., and D. S. Frederickson. 1982. Familial lipoprotein deficiency (abetalipoproteinemia and Tangier disease). In The Metabolic Base of Inherited Disease. J. B. Stanbury, J. B. Wijngaarden, D. S. Frederickson, J. L. Goldstein, and M. S. Brown, editors. McGraw-Hill, Inc., New York. 589-621.

17. Glickman, R. M., P. H. R. Green, R. S. Lees, S. E. Lux, and A. Kilgore. 1979. Immunofluorescence studies of apolipoprotein B in intestinal mucosa, absence in abetalipoproteinemia. Gastroenterology. 76: 288-292.

18. Muller, D. P. R., J. K. Lloyd, and A. C. Bird. 1977. Longterm management of abetalipoproteinemia, possible role for vitamin E. Arch. Dis. Child. 52:209-214.

19. Hegele, R. A., and A. Angel. 1985. Arrest of neuropathy and myopathy in abetalipoproteinemia with high-dose vitamin $\mathrm{E}$ therapy. Can. Med. Assoc. J. 132:41-44.

20. Silk, D. B. A. 1983. Nutritional Support in Hospital Practice. Blackwell Scientific Publications, Oxford. 123-124.

21. Redgrave, T. G., D. C. K. Roberts, and C. E. West. 1975. Separation of plasma lipoproteins by density gradient ultracentrifugation. Anal. Biochem. 65:42-49.

22. Spencer, K., and C. D. Price. 1979. Kinetic immunoturbidimetry. The estimation of albumin. Clin. Chim. Acta. 95:263-276.

23. Shulman, M., C. D. Wilde, and G. Koehler. 1978. A better cell line for making hybridomas secreting specific antibodies. Nature (Lond.). 276:269-270.

24. Milne, R. W., R. Theolis, Jr., R. B. Verdery, and Y. L. Marcel.
1983. Characterization of monoclonal antibodies against low density lipoprotein. Arteriosclerosis. 3:23-30.

25. Tokuyasu, K. T., and S. J. Singer. 1976. Improved procedures for immunoferritin labeling of ultrathin frozen sections. J. Cell Biol. 71: 894-898.

26. Slot, J. W., and H. J. Geuze. 1981. Sizing of protein A-colloidal gold probes for immunoelectronmicroscopy. J. Cell Biol. 90:533-540.

27. Slot, J. W., and H. J. Geuze. 1983. The use of protein A-colloidal gold (PAG) complexes as immunolabels in ultrathin frozen sections. In Immunohistochemistry. A. C. Cuello, editor. IBRO Handbook Series. John Wiley \& Sons, Chichester, England. 323-336.

28. Slot, J. W., and H. J. Geuze. 1985. A new method of preparing gold probes for multiple-labeling cytochemistry. Eur. J. Cell Biol. 38: 87-93.

29. Tokuyasu, K. T. 1978. A study of positive staining of ultrathin frozen sections. J. Ultrastruct. Res. 63:287-307.

30. Rachmilewitz, D., J. J. Albers, and D. R. Saunders. 1976. Apoprotein B in fasting and postprandial human jejunal mucosa. J. Clin. Invest. 57:530-533.

31. Glickman, R. M., J. Khorana, and A. Kilgore. 1976. Localization of apolipoprotein B in intestinal epithelial cells. Science (Wash. DC) 193:1254-1255.

32. Schonfeld, G., E. Bell, and D. H. Alpers. 1978. Intestinal apoproteins during fat absorption. J. Clin. Invest. 61:1539-1550.

33. Speelberg, B., D. W. Erkelens, L. Kater, and L. Havekes. 1984. Immunofluorescence of apoprotein A-I, A-II, B and E in non fatty and fatty human liver. Eur. J. Clin. Invest. 14:43. (Abstr.)

34. Geuze, H. J., J. W. Slot, P. A. van der Ley, and R. C. T. Scheffer. 1981. Use of colloidal gold particles in double labeling immuno-electronmicroscopy of ultrathin frozen tissue sections. J. Cell Biol. 89:653-665.

35. Christensen, N. J., C. E. Rubin, M. C. Cheung, and J. J. Albers. 1983. Ultrastructural immunolocalization of apolipoprotein B within human jejunal absorptive cells. J. Lipid Res. 24:1229-1242.

36. Alexander, C. A., R. L. Hamilton, and R. J. Havel. 1976. Subcellular localization of apoprotein $B$ of plasma lipoproteins in rat liver. J. Cell Biol. 69:241-263.

37. Lackner, K. J., J. C. Monge, S. W. Law., R. E. Gregg, and H. B. Brewer, Jr. 1985. Abetalipoproteinemia: analysis of hepatic $m$ RNA and gene coding for apolipoprotein B-100. Arteriosclerosis. 5:495a. (Abstr.) 